\title{
Design of pallet, frame and chain of soldering station conveyor
}

\author{
Mária Blatnická ${ }^{1, *}$, Milan Sága ${ }^{1}$, Miroslav Blatnický ${ }^{2}$ \\ ${ }^{1}$ Department of Applied Mechanics, Faculty of Mechanical Engineering, University of Žilina, \\ Univerzitná 1, 01026 Žilina, Slovak Republic \\ ${ }^{2}$ Department of Transport and Handling Machines, Faculty of Mechanical Engineering, University \\ of Žilina, Univerzitná 1, 01026 Žilina, Slovak Republic
}

\begin{abstract}
The paper deals with constructional procedure and design of the soldering station for compressor outlet piping. The design of the mechanism is based on the need to create a device that will be able to move the pallet with the compressor between individual operational positions of the entire conveyor line.
\end{abstract}

Keywords: Chain conveyor, constructional design, 3D modelling, soldering station

\section{Introduction}

The successful development of mankind to the state we see today has its origin in distant past when man had to fight for survival in the original living conditions. Repeating successful activities that have brought about improved living conditions has also triggered brain activity, i.e. from simple logical operations to memorization and analysis. The result of this process was the creations of man, whose improvement led to progress consisting of the construction of machines and heavy machinery. This process of developing technical systems that relieve man from repetitive physical work is called mechanization, and there is no need to talk too much about the importance of machinery for manipulating material. Mechanisation is an important means of increasing productivity, quality and competitiveness of production. The effort is to make the individual working operations as short and simple as possible and to make them easy to learn while demanding a minimum of human effort. Mechanisation greatly relieves man from heavy physical work, for example, in dangerous or harmful environments [1-3].

Today's advanced production is characterized by automation. Automation is a process in which the managerial function of a person is replaced by the activity of various machines and devices $[4,5]$. Automation is a very complex process including very simple control operations performed on a relatively simple devices, as well as very complex management of large production units. Controlling is a purposeful activity that evaluates and processes information about a controlled object or process, activities in that process (which may be data of measuring devices, statuses of signalising equipment and devices), and controls the devices in question to achieve the same prescribed purpose $[6,7,8]$ - in this case, it is the

\footnotetext{
${ }^{*}$ Corresponding author: maria.blatnicka@,fstroj.uniza.sk

Reviewers: Robert Grega, Kateryna Kravchenko
} 
aim of designing a chain conveyor (Fig. 1) for transporting a handling unit between individual working positions, the design must meet the requirements of the customer's technical standards. According to these standards and customer requirements, a flame soldering station for compressor outlet piping will be designed [9].

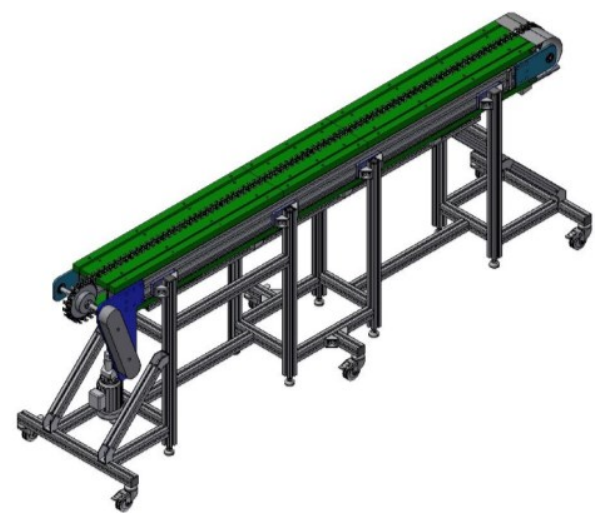

Fig. 1. 3D model of the chain conveyor design

\section{Device requirements}

The device should be formed by a chain conveyor with compressor pallets attached to it (Fig. 2). Pallets are formed to shape a tube and at the same time cover the compressor so that it is not damaged by the temperature field from the flame when welding. Technical description of the device positions:

Position 1: Manual loading the compressor into the pallet, loading the soldering ring and pipes.

Position 2: Flame welding. The pallet with compressor stops at the welding station, a burner (the entire Messer assembly) comes to the welding point and welding takes place. The compressor is mounted on the pallet in a slanting manner so that melt of the soldering ring flows towards the pipe joint.

Position 3: Is a manual station where an operator tests tightness manually by inserting the compressed air hose into the compressor tube and checks tightness with spray.

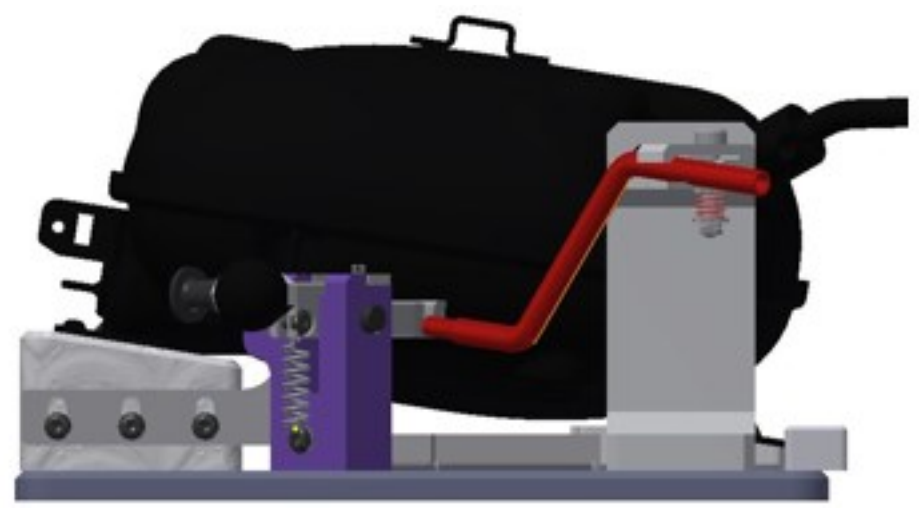

Fig. 2. 2D view of the compressor pallet design assembly

The design of a chain conveyor is based on a need to create device that is able to move the pallet with the component (SECOP compressor) from the first workstation (manual 
position - loading the compressor into the pallet, loading the soldering ring and pipe) successively through the second workplace containing flame welding (automatic position pressure pipe soldering) to the third position (checking and unloading the component into the pallet). The process itself consists of several steps. The choice of a suitable chain and drive is important, with consequent further calculations or selection of other conveyor components. Subsequently, a load-bearing structure will be created, in the creation of which it is desirable to adhere to the correct principles of construction methodology. From the given requirements it was necessary to choose basic dimensional parameters:
- Pallet length:
$L d p=250 \mathrm{~mm}$,
- Pallet width:
$L \check{s} p=250 \mathrm{~mm}$,
- Conveyor manipulator length:
- Total number of pallets:
$L D M=3,200 \mathrm{~mm}$, $i C=12(-)$.

\section{Pallet design}

Firstly, a design of the pallet with a bed for the outlet pipe soldered in position no. 2 was created. The design of the pallet began by selecting basic dimensions of a base plate (Fig. 3 ) and the subsequent two-pin bedding for centering the compressor to the desired position.
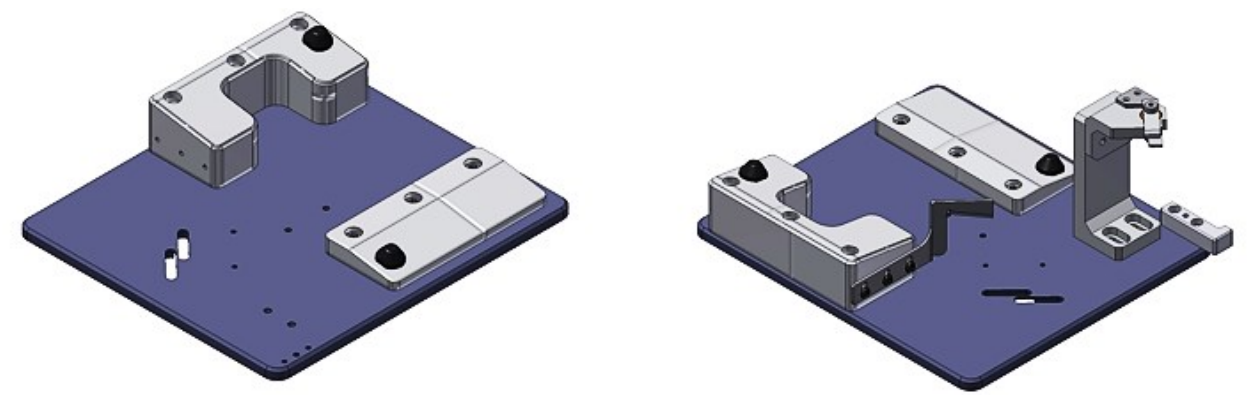

Fig. 3. Method of pallet design as a compressor attachment

As the component itself (the compressor) already has a considerable weight (6.5 kg), it was necessary to design the pallet so as to make it as lightweight as possible. This was the reason for choosing a base plate and 2 beds (Fig. 3 left) of AlMgSi07 material. After the compressor bed was placed, the design of the bed for the soldered pipe was created with securing against vertical displacement (Fig. 3 right) so that it was height adjustable. To ensure correct loading of the pipe in the horizontal position, it was necessary to design a flip-over locking mechanism for the soldering tube (red tube Fig. 5), which serves to accurately load the pipe and secure it in the desired soldering position.
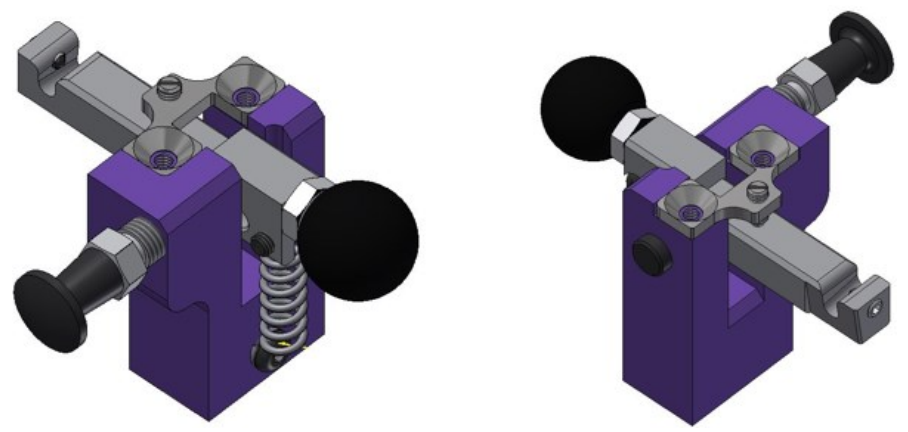

Fig. 4. Views of the locking mechanism design 
The proposed mechanism (Fig. 4) is designed so that it can be automatically locked off in position no. 2 for welding in a given location. Thus, the proposed pallet assembly includes a pallet base plate, a compressor bed, an anti-fall pipe locking device, and an outlet pipe housing.

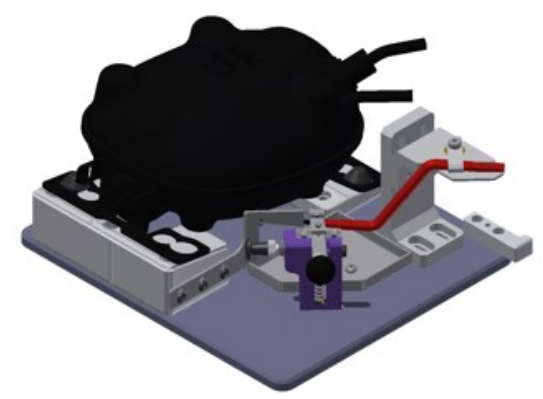

Fig. 5. 3D view of the compressor pallet design assembly

\section{Frame design}

When designing a frame, it was necessary to first choose the basic dimensions of the conveyor. The design was based primarily on the number of pallets on the device (12 pieces). Subsequently, the necessary spacing between the pallets and overall length of the frame was chosen. The support frame is designed from AL Bosch profile 80x120 mm (Fig. 6). Probably it was also possible to choose a profile with smaller dimensions but this type of beam was suitable for construction from a structural point of view [10-12].
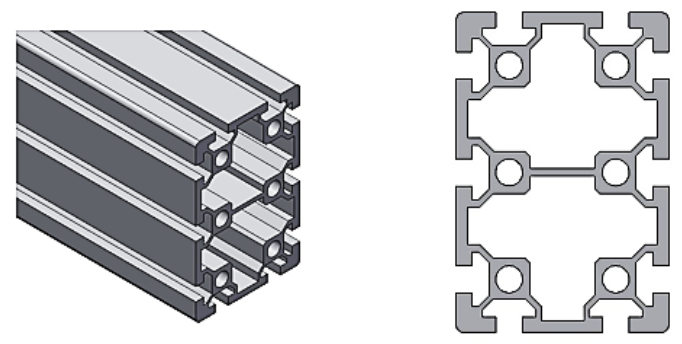

Fig. 6. Bosch Rexroth profile $80 \times 120 \mathrm{~mm}$

Struts and crossbeams are designed from the same profiles but with dimensions $45 \times 45$ $\mathrm{mm}$ (Fig. 7). Supporting profiles are joined by 90x90 $\mathrm{mm}$ angle bars and other profiles using $45^{\circ} 45 \times 45 \mathrm{~mm}$ angle bar and Bosch Rexroth pin joint.

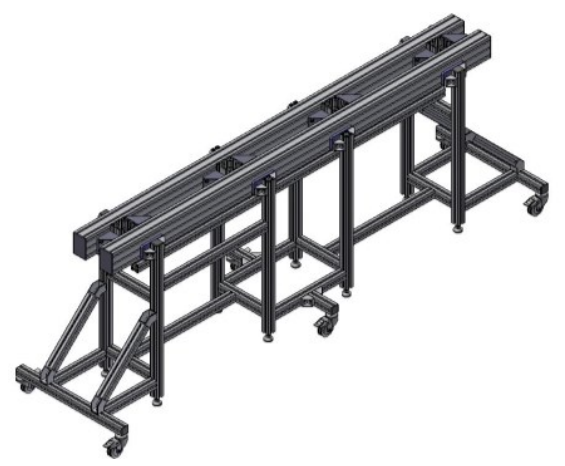

Fig. 7. Design of conveyor frame 


\section{Conveyor chain design}

After the design of the frame and subsequent placement of the pallets, the chain and the gearwheels could be made. Chains are dimensioned according to the maximum force in the chain resulting from all power losses and tension. Static and dynamic forces are created in the chain at motion. The main objective is to predict the power (and thus the size) of the engine and also to pre-determine the type of roller chain serving as a traction element. Determination of these two components is very important for the design because, for example, according to the chain, a suitable sprocket or chain guide must be selected. A choice of the engine and the gearbox affects a size of the drive shaft, bearings and spatial arrangement of the entire drive. Depending on the purpose of the conveyor, various types of chains can be used [13-15]. In this case, "standard roller chain with attachment 1 - DIN 8187 with bend attachment K1/01 double sided" for better pallet attachment (Fig. 8) was selected. The basic parameters required for the design of the chain drive were chosen according to Tab. 1 from HABERKORN.
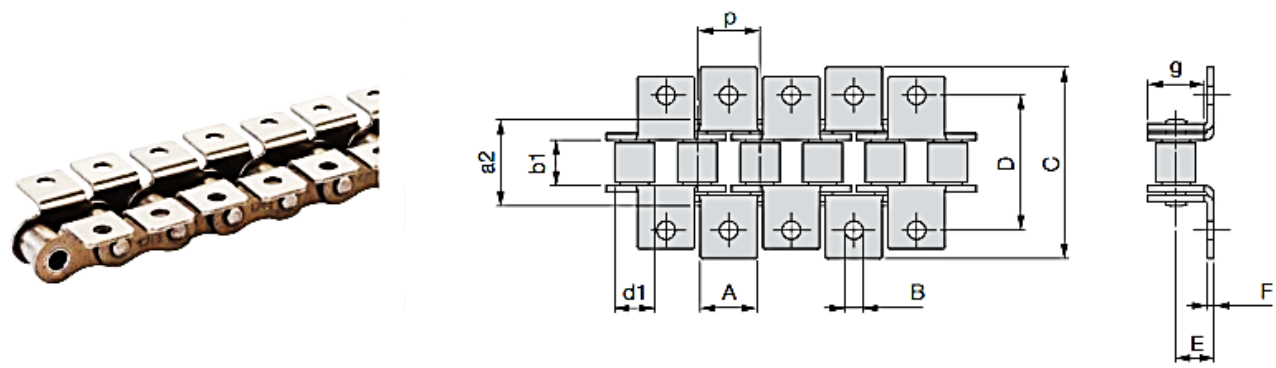

Fig. 8. Geometry of the selected chain

We select a chain with the label of link $10 \mathrm{~B}-15 / 8 \times 3 / 8$

Chain length / (number of links): $L R=5,820.6 \mathrm{~mm}$,

Pitch spacing of pallets: $R 1=485 \mathrm{~mm}$,

Pitch of first and last sprocket: $L R K=2,635.4 \mathrm{~mm}$.

Table 1. Chains from Haberkorn

\begin{tabular}{|c|c|c|c|c|c|c|c|c|c|c|c|c|c|c|c|}
\hline DIN IS & ore lal & $\begin{array}{l}\text { Pitch } \\
\text { p }\end{array}$ & $\begin{array}{l}\text { Width } \\
\text { b1 } \\
\text { min. }\end{array}$ & $\begin{array}{l}\text { Roller } \\
\text { d1 } \\
\text { max. }\end{array}$ & $\begin{array}{l}\text { a2 } \\
\text { max. }\end{array}$ & $\begin{array}{l}\mathbf{g} \\
\max .\end{array}$ & A & B & $\begin{array}{l}\text { C } \\
\text { max. }\end{array}$ & D & $E$ & $F$ & & $\begin{array}{l}\text { Mass } \\
\text { in } \mathrm{kg} / \mathrm{m}\end{array}$ & $\begin{array}{l}\text { Order } \\
\text { code }\end{array}$ \\
\hline 6 B-1 & So A & 9.525 & 5.72 & 6.35 & 13.5 & 8.26 & 8.0 & 3.5 & 27.0 & 19.0 & 6.5 & 1.03 & 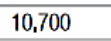 & 0.61 & 552666 \\
\hline $88 \mathrm{~B}-1$ & $1 / 2 " \times 5 / 16^{\prime \prime}$ & 12.700 & 7.75 & 8.51 & 17.0 & 11.81 & 9.5 & 4.3 & 37.2 & 28.2 & 8.4 & 1.40 & 21,100 & 1.01 & 552692 \\
\hline 10 B-1 & $5 / 8^{\prime \prime} \times 3 / 8^{\prime \prime}$ & 15.875 & 9.65 & 10.16 & 19.6 & 14.73 & 14.1 & 5.2 & 47.6 & 31.8 & 10.4 & 1.63 & 7.400 & 1.32 & 552726 \\
\hline 12B-1 & $3 / 4^{\prime \prime} \times 7 / 16^{\prime \prime}$ & 19.050 & 11.68 & 12.07 & 22.7 & 16.13 & 15.8 & 5.6 & 51.6 & 35.0 & 12.0 & 1.80 & 32,300 & 1.66 & 552689 \\
\hline $6 \mathrm{~B}-1$ & $1 " x 17.02 \mathrm{~mm}$ & 25.400 & 17.02 & 15.88 & 36.1 & 21.08 & 19.0 & 6.8 & 74.8 & 50.8 & 15.9 & 3.00 & 70,600 & 4.27 & 552716 \\
\hline
\end{tabular}

\section{Design of chain drive and tensioner}

For most applications, drive and tensioner are two separate units. According to the design methodology, it is appropriate to place the drive at the beginning of the conveyor and the tensioning unit at its end $[16,17]$. A plate is rigidly screwed by four screws onto the frame of the conveyor beam. To this plate is mounted a gearbox with an electric motor. There is a secondary drive shaft with a sprocket (Fig. 9 left) located together with the chain transmission from the electric motor to the main drive shaft. Chain transmission is made by a pair of wheels with the dimensions shown in Tab. 2. 
Table 2. Sprocket wheels dimensions

\begin{tabular}{|c|c|c|c|c|c|c|c|}
\hline Usage & $\begin{array}{c}\text { Number } \\
\text { of teeth }\end{array}$ & $\begin{array}{c}\boldsymbol{d}_{\boldsymbol{e}} \\
{[\mathbf{m m}]}\end{array}$ & $\begin{array}{c}\boldsymbol{d}_{\boldsymbol{p}} \\
{[\mathbf{m m}]}\end{array}$ & $\begin{array}{c}\boldsymbol{D} \mathbf{1} \\
{[\mathbf{m m}]}\end{array}$ & $\begin{array}{c}\boldsymbol{B} \mathbf{1} \\
{[\mathbf{m m}]}\end{array}$ & $\begin{array}{c}\text { Profile } \\
\text { radius of } \\
\text { curvature } \\
\mathbf{r 3}[\mathbf{m m}]\end{array}$ & $\begin{array}{c}\text { Tooth } \\
\text { curvature } \\
\boldsymbol{C} \text { [mm] }\end{array}$ \\
\hline $\begin{array}{c}\text { Sprockets of the } \\
\text { conveyor }\end{array}$ & 18 & 78 & 73.14 & 35 & 7 & 13 & 1.3 \\
\hline $\begin{array}{c}\text { Drive wheel of } \\
\text { the shaft and } \\
\text { transmission }\end{array}$ & 15 & 65.9 & 61.09 & 35 & 7 & 13 & 1.3 \\
\hline
\end{tabular}

On the main drive shaft there is a bearing housing, clamping sleeves with a torque limit and a corresponding sprocket. For safety reasons, the limiter is used on all drives. In the case of undesirable collision, the load increases and the critical torque is exceeded. At this point, the limiter ensures slipping of the shaft and the sprocket. The main drive gear on the shaft is secured by two 250.0120 Halder clamping sleeves (Fig. 9 right) on both sides.
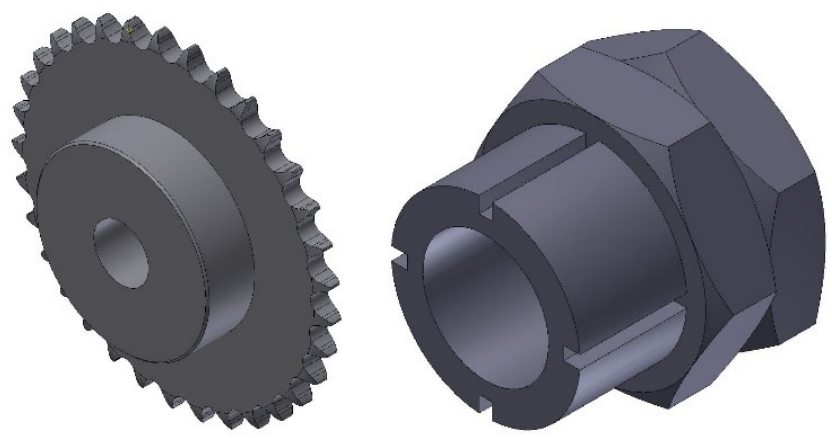

Fig. 9. Drive sprocket (left) and clamping case 250.0120 Halder (right)

The shaft is stored in bearings that are pressed in the housing in the base plate. The shaft is secured with a securing ring against axial movement. The complete proposed drive device is shown in Fig. 10 left. The reversing tensioning part consists of a gear that is mounted in bearings fixed in solid housings in the same way as on the driving part.
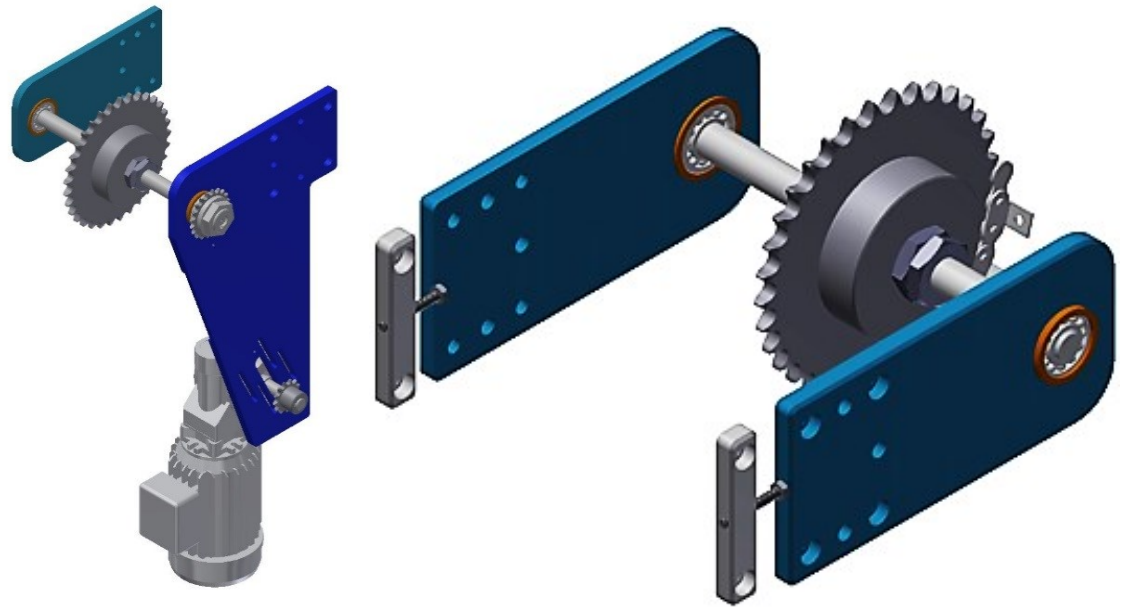

Fig. 10. Designed drive unit (left) and tensioning device (right) 
If the wheel fastening is firm, the chain is tensioned by its own weight $[18,19]$. In the case of using sliding housings on the driven side, a chain is tensioned by a pair of tensioning screws. The tensioning force used to be between 1,000 and 4,000 N. The conveyor is driven by an electric motor through the spur gearbox. This power station is located below the conveyor. For safety reasons, the drive chain will be covered.

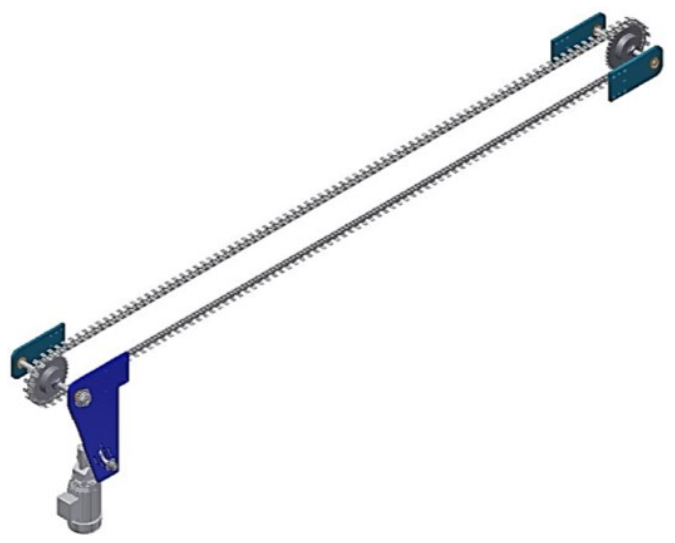

Fig. 11. Overview of the drive, chain and tensioning device of the proposed chain conveyor

\section{Conclusion}

The aim of the article was to partially design a chain conveyor of an automatic soldering station consisting of the bearing pallet design, which is also a jig (tool) for ensuring the correct position of the compressor and the pipe; the conveyor frame design from standardized profiles from Bosch and the design of the chain with its drive and tensioning device. We can say that this goal has been met. In the next step of solving this problem, it will be necessary to design support and guide of the chain links, to propose design solutions of the individual work positions of the station and to make a dimensional calculation of the driving electric motor. After this step, the prototype of the flame soldering station for compressor outlet piping can be manufactured and brought into operation.

This work has been supported by KEGA project No. 015ŽU-4/2017.

\section{References}

1. M. Macko, J. Flizikowski, Z. Szczepański, K. Tyszczuk, G. Śmigielski, A. Mroziński, J. Czerniak, A. Tomporowski, CAD/CAE applications in mill's design and investigation. Proceedings of the 13th International Scientific Conference on Computer Aided Engineering, Springer International Publishing AG, Lecture Notes in Mechanical Engineering, Chapter 35, 343-351 (2017)

2. R. Halama, M. Fusek, Z. Poruba, Influence of mean stress and stress amplitude on uniaxial and biaxial ratcheting of ST52 steel and its prediction by the AbdelKarimOhno model. International Journal of Fatigue 91, 313-321 (2016)

3. J. Vavro, J. Vavro jr., P. Kováčiková, P. Kopas, M. Handrik, Simulation and analysis of defect distribution in passenger car tire under dynamic loading. Applied Mechanics and Materials 611, $544-547$ (2014)

4. J. Gerlici, T. Lack, J. Harušinec, Realistic simulation of railway operation on the RAILBCOT test stand. Applied mechanics and materials 486, 387-395 (2014) 
5. A. Sapietová, V. Dekýš, M. Sapieta, P. Pecháč, Application of computational and design approaches to improve carrier stability. Procedia Eng. 96, 410-418 (2014)

6. J. Czerniak, D. Ewald, M. Macko, G. Śmigielski, K. Tyszczuk, Approach to the Monitoring of Energy Consumption in Eco-grinder Based on ABC optimization, in: S. Kozielski et al. (Eds.): BDAS 2015, Communications in Computer and Information Science 521, 516-529, (2015)

7. P. Št'astniak, M. Moravčík, Freight bogie prototype properties analysis by means of simulation computations. Manufacturing technology 17 (3), 381-388 (2017)

8. G. Domek, A. Kołodziej: Design of the tendon structure in timing belts Procedia Engineering 136, 365-369 (2016)

9. J. Galliková, R. Poprocký, P. Volna, Implementation of FMEA method in maintenance of semi-trailer combination. Diagnostyka 17 (4), 85-92 (2016)

10. V. Bulej, J. Uricek, V. Poppeova, R. Zahoransky, M. Rupikova, Study of the Workspace of Hybrid Mechanism Trivariant. Appl. Mech. and Mat., Mech. Eng. and Manufacturing 436, 366-373 (2013)

11. J. Stancek, V. Bulej, Design of driving system for scissor lifting mechanism. Acad. J. of Manufacturing Eng. 13, 38-43 (2015)

12. M. Cisar, I. Kuric, N. Cubonova, Proposal of device for monitoring of educational machine tools. Advances in Sci. and Technology-Res. J. 31, 80-86 (2016)

13. M. Dudziak, G. Domek, A. Kołodziej, K. Talaśka, Contact Problems Between the Hub and the Shaft with a Four-Angular Shape of Cross-Section for Different Angular Positions. Applied Mechanics and Materials 816, 54-62 (2015)

14. J. Vavro jr., J. Vavro, P. Kováčiková, P. Kopas, M. Handrik, R. Bezdedová, Numerical analysis of stress states for graphitic cast iron structures. Applied Mechanics and Materials 611, 252-255 (2014)

15. J. Gerlici, T. Lack, Railway wheel and rail head profiles development based on the geometric characteristics shapes. Wear: an international journal on the science and technology of friction, lubrication and wear 271 (1-2), 246-258 (2011)

16. G. Śmigielski, W. Toczek, R. Dygdała, K. Stefański, Metrological analysis of precision of the system of delivering a water capsule for explosive production of water aerosol. Metrology and Measurement Systems, 23 (1), 47-58 (2016)

17. M. Sapieta, A. Sapietová, L. Gajdoš, Determine the fatigue life of flange of bearings test station. Procedia Engineering 177, 548-553 (2017)

18. R. Halama, M. Fusek, F. Fojtík, An industrial application of a method for spatial motion measurement. EAN 2010, 48 ${ }^{\text {th }}$ International Scientific Conference on Experimental Stress Analysis, 75-80 (2010)

19. M. Handrik, M. Vaško, P. Kopas, V. Mozer, The linear and nonlinear stability loss of structures due to thermal load. Procedia Engineering 136, 359-364 (2016) 